\title{
FAKTOR-FAKTOR YANG MEMPENGARUHI PARTISIPASI MASYARAKAT DALAM PENGELOLAAN SAMPAH PADAT DI DENPASAR TIMUR
}

\author{
Dewa Ayu Agustini Posmaningsih \\ Dosen Jurusan Kesehatan Lingkungan Poltekkes Denpasar \\ dewaayuposmaningsih@yahoo.co.id
}

\begin{abstract}
Urban waste management also has the driving factors and inhibitors in an effort to increase community participation in waste management. The research objective is to find out how much the relationship of factors predisposing, enabling and reinforcing community participation in solid waste management. The design of this study include observational research with cross sectional. The sample size is 180 housewife and the sample was collected through stratified random sampling. The results showed there is a relationship of knowledge and attitudes towards participation in waste management with the knowledge of determination of $20.6 \%$ and $24.9 \%$ for attitude determination. Facilities management of community participation in waste management with the determination of $36.2 \%$. Relationship local agencies, community leaders and economic benefits of community participation in waste management by local institutions determination of $10.3 \%$, determination of public figures by $8.5 \%$, and the determination of the economic benefits of $35.9 \%$. Facility factors, economic benefits, local institutions, knowledge and attitudes to contribute jointly to the participation of the determination of $65.1 \%$. The conclusions of this study is a factor predisposing, enabling and reinforcing related to public participation. Factors of knowledge, attitudes, facilities, local agencies, and economic benefits together to contribute to community participation. It is recommended that local governments provide guidance to local agencies in participatory planning of environmentally sound and sustainable solid waste management.
\end{abstract}

Keywords: Predisposing, enabling, reinforcement factors, community participation

\begin{abstract}
Abstrak: Pengelolaan sampah perkotaan juga memiliki faktor pendorong dan penghambat dalam upaya untuk meningkatkan partisipasi masyarakat dalam pengelolaan sampah. Tujuan penelitian ini adalah untuk mengetahui seberapa besar hubungan faktor predisposisi, pendukung dan pendorong partisipasi masyarakat dalam pengelolaan sampah. Desain penelitian ini termasuk penelitian observasional dengan cross sectional. Ukuran sampel adalah $180 \mathrm{ibu}$ rumah tangga dan sampel dikumpulkan melalui stratified random sampling. Hasil penelitian menunjukkan ada hubungan pengetahuan dan sikap terhadap partisipasi dalam pengelolaan sampah dengan pengetahuan. Kesimpulan dari penelitian ini adalah faktor predisposisi, pendukung dan pendorong terkait dengan partisipasi masyarakat. Faktor pengetahuan, sikap, fasilitas, lembaga lokal, dan manfaat ekonomi bersamasama untuk memberikan kontribusi terhadap partisipasi masyarakat. Kepada pemerintah daerah disarankan memberikan bimbingan kepada lembaga lokal dalam perencanaan partisipatif dari pengelolaan sampah yang berwawasan lingkungan dan berkelanjutan.
\end{abstract}

Kata kunci: Faktor predisposisi, pendukung, penguat, partisipasi masyarakat 


\section{Pendahuluan}

Di kota besar sampah menjadi permasalahan baik dari segi jumlah maupun jenisnya. Permasalahan sampah sangat berkaitan dengan laju pertumbuhan penduduk, peningkatan teknologi serta aktivitas sosial budaya dan ekonomi masyarakat ${ }^{1}$. Kota Denpasar sebagai pusat Ibu Kota Propinsi Bali dan sekaligus pusat pemerintahan dan perekonomian mempunyai daya tarik tersendiri bagi penduduk pendatang. Jumlah timbulan sampah harian Kota Denpasar ratarata $4.703,07 \mathrm{~m}^{3}$ per harinya $47,41 \%$ adalah sampah organik dan 52,59\% sampah anorganik. Karakteristik sampah anorganik yang dihasilkan adalah 22\% sampah plastik, 24,67\% kertas dan 4,83\% sampah anorganik lainnya ${ }^{2}$.

Beberapa faktor yang mempengaruhi partisipasi masyarakat dalam kegiatan pengelolaan sampah di antaranya: 1) Jenis kelamin; 2) Usia; 3) Pendidikan; 4) Informasi; 5) Akses ke program daur ulang; 6) Insentif; 7) lembaga lokal dan 8) Block leader 3,4,5,6. Pengelolaan sampah perkotaan juga memiliki faktor-faktor pendorong dan penghambat dalam upaya peningkatan partisipasi masyarakat.
Menurut hasil penelitian Nitikesari (2005), faktor-faktor tersebut di antaranya tingkat pendidikan, penempatan tempat sampah di dalam rumah, keberadaan pemulung, adanya aksi kebersihan, adanya peraturan tentang persampahan beserta penegakan hukumnya.

Partisipasi masyarakat di Denpasar Timur dapat ditingkatkan dengan terlebih dahulu mengetahui faktor-faktor yang berhubungan., ${ }^{7,8}$ Penelitian ini bertujuan untuk mengetahui hubungan faktor predisposisi, pemungkin dan penguat terhadap partisipasi masyarakat dalam pengelolaan sampah di kecamatan Denpasar Timur.

Berbagai metode dikembangkan untuk mengintervensi perilaku manusia menjadi lebih ramah lingkungan (pro environment behaviour). Wanita cenderung berpartisipasi lebih aktif dalam kegiatan pengelolaan sampah domestik berdasarkan suatu program yang diberikan. Informasi yang didukung dengan alasan-alasan ekonomi dan lingkungan mampu mengubah perilaku seseorang pada sampah. Informasi tentang kegiatan dilaksanakan dan kepercayaan masyarakat atas kemampuan yang 
dimiliki untuk melaksanakannya harus jelas, menghindari kemungkinan terjadinya konflik dan dapat menjamin keberhasilan dari kegiatan. ${ }^{9,10,11}$

Insentif berpengaruh mendorong tingkah laku ramah lingkungan terutama pada masyarakat dengan golongan ekonomi rendah. Di India perencanaan pemberian insentif pada masyarakat yang berpartisipasi dapat memberikan insipirasi atau memberikan ajakan kepada masyarakat lain untuk melakukan hal yang sama. $4,6,11,12,13,14,15$

\section{Informasi kontak langsung} mempengaruhi tingkat partisipasi secara signifikan dibandingkan dengan informasi tanpa kontak langsung. Block leaders berperan dalam melakukan pendekatanpendekatan personal seperti hasil penelitian di Kampung Banjarsari Jakarta Selatan dengan nilai asosiasi 0,508 . Penelitian yang dilakukan di Minnesota menunjukkan bahwa jika masyarakat mendapatkan manfaat yang cukup besar dengan biaya yang terbatas dengan cara pendekatan komunitas menunjukkan peningkatan efisiensi yang cukup besar terhadap program ramah lingkungan. ${ }^{6,1416}$
Pemimpin lokal atau pemimpin agama memberikan pengaruh yang sangat besar terhadap partisipasi masyarakat. Community Leaders adalah seseorang yang yang sangat berperan dalam upaya promosi partisipasi masyarakat dalam pengumpulan sampah dengan pembayaran retribusi, pemisahan sampah, dan melakukan pengawasan dari pelaksanaan kegiatan. ${ }^{6,12}$

Berdasarkan hasil penelitian Tandipanga di RW 11 Cibangkong terlihat bahwa lembaga lokal sangat berpengaruh terhadap efektifitas pengelolaan sampah. Kepemilikan fasilitas, sarana untuk pengolahan sampah akan memberikan pengaruh terhadap pengelolaan sampah di rumah tangga., 5

Pengetahuan memberikan pengaruh terhadap partisipasi masyarakat . Pendapatan masyarakat yang relatif tinggi, memungkinkan seseorang tidak hanya memikirkan upaya memenuhi kebutuhan hidup sehari-hari, akan tetapi dapat membagi dan menyisihkannya untuk kebutuhan hidup yang lain seperti menyediakan sarana prasarana untuk menampung dan mengelolan sampah rumah tangga. ${ }^{17,18}$ Sikap, persepsi dan 
pengalaman atas masalah sampah memberikan pengaruh terhadap partisipasi masyarakat dalam pengelolaan sampah. Ini sesuai dengan hasil penelitian studi kasus Muller pada tahun 2002 tentang pengelolaan sampah di Nagapura, Bangalore. $^{4,6,12}$

\section{Metode Penelitian}

Jenis penelitian termasuk penelitian observational. Penelitian adalah penelitian kuantitatif. Rancang bangun penelitian cross sectional. Lokasi penelitian ini adalah di Kecamatan Denpasar Timur Kota Denpasar

Data primer dalam penelitian ini adalah skor partisipasi masyarakat, pengetahuan, sikap masyarakat, kondisi fasilitas pengelolaan sampah rumah tangga, lembaga lokal, tokoh masyarakat, dan manfaat ekonomi kegiatan pengelolaan sampah. Data sekunder yang dipergunakan dalam penelitian meliputi gambaran geografi, topografi, kependudukan dan mana-jemen pengelolaan sampah di Denpasar Timur. Instrumen yang digunakan dalam penelitian ini adalah kuesioner.

Responden dalam penelitian ini adalah ibu rumah tangga.
Populasi dalam penelitian berjumlah 39.356 rumah tangga. Sampel penelitian dibagi menjadi dua kelompok berdasarkan sistem pengelolaan sampah yaitu kelompok sampel yang berasal dari Desa Swakelola dan kelompok sampel dari Desa Non Swakelola. Besar sampel diambil untuk penelitian cross sectional dengan menggunakan rumus ${ }^{19}$ yaitu :

$$
\begin{aligned}
& n=Z_{1-\alpha / 2}^{2} \frac{P(1-P)}{d^{2}}= \\
& n=1,96^{2} \frac{0,12(1-0,12)}{0,05^{2}}
\end{aligned}
$$

$164+10 \% \approx 180$

Variabel bebas penelitian adalah pengetahuan, sikap, fasilitas pengelolaan sampah, lembaga lokal, tokoh masyarakat, dan manfaat ekonomi. Variabel terikat dalam penelitian ini adalah partisipasi masyarakat dalam pengelolaan sampah rumah tangga. Analisis penelitian adalah deskriptif, uji asumsi klasik dan analisis regresi linier berganda.

\section{Hasil Penelitian}

Hasil analisis univariat variabel partisipasi masyarakat, pengetahuan, sikap, fasilitas pengelolaan sampah, lembaga lokal, 
tokoh masyarakat dan manfaat ekonomi secara rinci pada Tabel 1. Variabel pengetahuan didapatkan nilai rata-rata total skor adalah 18,04 $\pm 2,40$ dengan skor minimum 11 dan skor maksimum 22.

Tabel 1

Distribusi Partisipasi Masyarakat, Pengetahuan, Sikap, Fasilitas Peran Lembaga Lokal, Tokoh Masyarakat dan Manfaat Ekonomi Dalam Pengelolaan Sampah

\begin{tabular}{lcccc}
\hline \multicolumn{1}{c}{ Variabel } & $\begin{array}{c}\text { Nilai Minimum } \\
\text { (Skor) }\end{array}$ & $\begin{array}{c}\text { Nilai Maksimum } \\
\text { (Skor) }\end{array}$ & Mean & SD \\
\hline Partisipasi Masyarakat & 3 & 13 & 8,44 & 3,05 \\
Pengetahuan & 11 & 22 & 18,04 & 2,40 \\
Sikap & 11 & 39 & 30,98 & 4,74 \\
Fasilitas pengelolaan & 1 & 14 & 8,46 & 2,49 \\
sampah & & & & \\
Lembaga Lokal & 0 & 28 & 11,81 & 8,60 \\
Tokoh Masyarakat & 0 & 14 & 5,42 & 4,24 \\
Manfaat Ekonomi & 0 & 8 & 4,73 & 1,44 \\
\hline
\end{tabular}

\section{Analisis Regresi Linier Sederhana}

Hasil uji bivariat dengan analisis regresi linier sederhana bahwa seluruh variabel prediktor yaitu pengetahuan, sikap, fasilitas, lembaga lokal, tokoh masyarakat dan manfaat ekonomi masing-masing memberikan kontribusi terhadap partisipasi masyarakat dalam pengelolaan sampah. Hasil regresi sederhana dapat dilihat pada tabel berikut :

Tabel 2

Nilai Koefisien Regresi Linier Sederhana Partisipasi Masyarakat Dalam Pengelolaan Sampah Di Kecamatan Denpasar Timur Tahun 2012

\begin{tabular}{lcccccc}
\hline \multicolumn{1}{c}{ Variabel Penelitian } & $\mathrm{B}$ & Nilai t & Sig & $\mathrm{R}^{2}$ & $\mathrm{~F}$ & Sig \\
\hline Pengetahuan & & & & & & \\
Konstanta & $-1,944$ & $-1,262$ & 0,209 & 0,206 & 46,30 & 0,00 \\
$\begin{array}{l}\text { Pengetahuan } \\
\text { Sikap }\end{array}$ & 0,576 & 6,804 & 0,000 & & & \\
Konstanta & $-1,487$ & $-1,136$ & 0,258 & 0,249 & 58,87 & 0,00 \\
Sikap & 0,321 & 7,673 & 0,000 & & & \\
$\begin{array}{l}\text { Fasilitas } \\
\text { Konstanta }\end{array}$ & $-2,227$ & 3,458 & 0,001 & 0,362 & 101,20 & 0,00 \\
$\begin{array}{l}\text { Fasilitas } \\
\text { Lembaga Lokal }\end{array}$ & 0,735 & 10,060 & 0,026 & & & \\
Konstanta & & & & & & \\
Lembaga lokal & 7,103 & 19,346 & 0,000 & 0,103 & 20,38 & 0,00 \\
Tokoh Masyarakat & 0,114 & 4,515 & 0,000 & & & \\
\hline
\end{tabular}




\begin{tabular}{lcccccc}
\hline Konstanta & 7,309 & 20,616 & 0,000 & 0,085 & 16,49 & 0,00 \\
Tokoh Masyarakat & 0,209 & 4,062 & 0,000 & & & \\
Manfaat Ekonomi & & & & & & \\
Konstanta & 2,436 & 3,875 & 0,000 & 0,359 & 99,741 & 0,00 \\
Manfaat Ekonomi & 1,271 & 9,987 & 0,000 & & & \\
\hline
\end{tabular}

Model persamaan yang terbentuk dari variabel fasilitas adalah Y $=-2,227+0,735$ (fasilitas), kualitas persamaan menunjukkan hubungan linier karena nilai $F(101,20)$ dengan Sig $\mathrm{F}_{\text {reg }}(0,00)<0,05$. Hal ini berarti model regresi antara variabel fasilitas dan partisipasi adalah signifikan dan linier.

\section{Pengaruh variabel predisposisi,} pemungkin dan penguat

Oleh karena semua uji asumsi klasik sudah terpenuhi dalam penelitian ini, maka analisis statistik inferensial atau statistik parametrik dengan menggunakan model analisis regresi linier berganda dapat dilanjutkan. Metode analisis yang dipergunakan adalah metode forward. Hasil analisis multivariat yang menghasilkan persamaan regresi :

$\mathrm{Y}=-5,830+0,163 \mathrm{X}_{1}($ pengetahuan $)+0,080$ $\mathrm{X}_{2}($ sikap $)+0,564 \mathrm{X}_{3}$ (fasilitas) $+0,086 \mathrm{X}_{4}$ (lembaga lokal) $+0,651 \quad \mathrm{X}_{6}$ (manfaat ekonomi)

\section{Pembahasan}

Kontribusi Pengetahuan dan Sikap Responden
Hasil penelitian menunjukkan terdapat hubungan yang signifikan variabel pengetahuan terhadap partisipasi masyarakat dalam pengelolaan sampah dengan determinasi sebesar $20,6 \%$. Pengetahuan dapat dipakai sebagai prediktor partisipasi masyarakat dalam pengelolaan sampah di Kecamatan Denpasar Timur. Variabel sikap memiliki kontribusi yang signifikan terhadap partisipasi sebesar 24,9\%. Sikap dapat disebut sebagai prediktor terjadinya partisipasi masyarakat atau sebagai faktor determinan partisipasi masyarakat dalam pengelolaan sampah.

Pengetahuan dan sikap menurut teori Lawrencen Green (1991) adalah faktor predisposisi dalam perubahan perilaku manusia. Faktor predisposisi merupakan faktor yang ada dalam diri seseorang. Pengetahuan dan sikap seseorang akan berperan dalam tindakan yang dilakukannya. $^{20}$

Hal ini sesuai dengan hasil penelitian Dewi bahwa pengetahuan 
memberikan pengaruh pada partisipasi masyarakat. Penyebab perubahan perilaku seseorang menjadi ramah lingkungan (pro environmental behaviour) adalah informasi yang spesifik ke bidang yang diharapkan. Informasi yang dibutuhkan oleh masyarakat adalah bukan saja hanya informasi yang bersifat menyampaikan bagaimana pengelolaan sampah yang baik akan tetapi lebih harus ditekankan pada informasi yang mendorong masyarakat untuk merubah perilaku. Jenis informasi yang perlu dipertimbangkan adalah informasi yang didukung oleh alasan ekonomi dan lingkungan serta informasi yang spesifik tentang kegitan daur ulang. ${ }^{10,11,14,17}$

Menurut Wardani, sikap atas masalah sampah memberikan pengaruh terhadap partisipasi masyarakat dalam pengelolaan sampah dengan nilai asosiasi 0,428. Timbulnya tanggapan atau respon dari masyarakat untuk berpartisipasi dalam bentuk swadaya, dipengaruhi oleh sikap, persepsi dan pengalamannya. Hasil penelitian Muller tahun 2002 tentang pengelolaan sampah di Nagapura, Bangalore, menyatakan bahwa partisipasi masyarakat tentang pengelolaan sampah rumah tangga akan meningkat seiring dengan meningkatnya kesadaran masyarakat. Penelitian pengelolaan sampah permukiman berbasis masyarakat di Taiwan memper-lihatkan bahwa perilaku masyarakat mendaur ulang sampah dipengaruhi oleh sikap, norma dan pengendalian perilaku. $^{4,6,12,21}$

\section{Kontribusi Fasilitas}

Hasil penelitian menunjukkan bahwa ketersediaan fasilitas memiliki kontribusi terhadap partisipasi masyarakat sebesar 36,2\%. Hasil penelitian Wardhani sebanyak 90,5\% masyarakat yang belum melakukan pemilahan, bersedia melakukan pemilahan apabila diberikan tempat sampah yang sesuai. Penelitian Dewi kepemilikan fasilitas, sarana untuk pengolahan sampah akan memberikan pengaruh terhadap pengelolaan sampah di rumah tangga, dimana alasan tidak melakukan pengelolaan sampah disebabkan karena tidak mempunyai alat sebesar $26,67 \%$. Pembebanan biaya yang lebih tinggi pada setiap kantong sampah yang dikeluarkan oleh rumah tangga untuk diolah oleh pengelola sampah akan 
memberikan dampak dalam pengurangan jumlah sampah yang diserahkan kepada pengelola. Hasil penelitian Fisher, Bell dan Baum (1984), keberadaan tempat sampah mengurangi pembuangan sampah sembarangan sebanyak $15 \%$ di daerah perkotaan dan $30 \%$ di jalan raya. Tempat sampah yang berwarna-warni bisa mengurangi pembuangan sampah sembarangan sebanyak 14,9\% sedangkan tempat sampah biasa hanya $3,15 \%$. Tempat sampah yang berbentuk unik dengan warna yang mencolok lebih efektif daripada tempat sampah biasa. ${ }^{6,17,22}$

\section{Kontribusi Lembaga Lokal, Tokoh} Masyarakat dan Manfaat Ekonomi

Green, menyatakan bahwa tokoh masyarakat merupakan tokoh sentral yang menjadi acuan masyarakat dalam berperilaku. Adanya dukungan yang positif dari tokoh masyarakat merupakan salah satu faktor pendorong untuk terjadinya perubahan perilaku. Kircht dan Becker menyatakan bahwa tokoh masyarakat adalah merupakan salah satu faktor yang mempengaruhi perubahan perilaku kesehatan. 5,20,23,24

Hasil penelitian menunjukkan bahwa terdapat kontribusi signifikan yang diberikan lembaga lokal dalam partisipasi masyarakat dalam pengelolaan sampah. Besar kontribusi variabel lembaga lokal adalah sebesar 10,3\%. Peran lembaga lokal memberikan informasi kepada masyarakat dan fasilitator dalam perubahan perilaku.

Hasil penelitian hubungan tokoh masyarakat dengan partisipasi masya-rakat menunjukkan tokoh masyarakat memiliki kontribusi yang signifikan terhadap partisipasi masyarakat sebesar $8,5 \%$. Block leaders adalah seseorang berperan dalam melakukan pendekatanpendekatan personal. Penelitian yang dilakukan di Minnesota menunjukkan bahwa peningkatan efisiensi program ramah lingkungan akan terjadi apabila masyarakat mendapatkan manfaat yang cukup besar dengan biaya program yang terbatas. Block leaders memberikan pengaruh terhadap partisipasi masyarakat dalam pengelolaan sampah rumah tangga di Kampung Banjarsari Jakarta Selatan. Kontribusi block leaders sangat ditentukan oleh keaktifan dan pemahaman dari block leaders. , $^{6,14}$

Faktor lain dalam faktor penguat adalah manfaat ekonomi 
yang dirasakan oleh masyarakat dalam perubahan suatu perilaku. Insentif merupakan salah satu faktor yang sangat penting untuk meningkatkan motivasi masyarakat. Hasil penelitian menunjuk-kan bahwa variabel manfaat ekonomi memberikan kontribusi yang signifikan terhadap partisipasi masyarakat sebesar 35,9\%. Hasil penelitian sesuai dengan hasil penelitian Wardani dimana insentif berupa benda dan dana dapat meningkatkan partisipasi dengan nilai asosiasi sebesar 0,524. Di India perencanaan pemberian insentif kepada masyarakat yang berpartisipasi dapat memberikan insipirasi atau memberikan ajakan kepada masyarakat lain untuk melakukan hal yang sama. Beberapa penelitian yang dilaksanakan oleh Laura Moningka tahun 2000, Reid tahun 2000, dan The National Environment Justice Advisory Council, 2000 menunjukkan hasil bahwa keberhasilan partisipasi masyarakat disebabkan oleh adanya insentif memberikan penghargaan pada masyarakat yang telah melaksanakan pengelolaan sampah. ${ }^{4,6,12,15}$
Insentif berpengaruh dalam mendorong tingkah laku ramah lingkungan terutama pada masyarakat dengan golongan ekonomi rendah. Menurut Gardner (1996), partisipasi masyarakat akan meningkat tajam ketika insentif finansial disediakan bagi program-program berbasis masyarakat yang telah berjalan. Berdasarkan hasil prediksi ekonomi dapat disimpulkan bahwa pembebanan biaya yang lebih tinggi setiap kantong sampah yang dihasilkan oleh masyarakat akan mem-berikan dampak adanya pengurangan permintaan pengumpulan sampah. Peningkatan pendapatan masyarakat akan meningkatkan jumlah sampah yang dibuang. Pemberian insentif berupa uang, hadiah adalah merupakan salah satu metode reinforcement yaitu positive reinforcement. Sedangkan negative reinforcement pemberian stimulus/ rangsangan yang bersifat negatif, misalnya denda jika melakukan sesuatu yang salah. ${ }^{11,14,22}$

\section{Kontribusi Faktor Predisiposisi,} Pemungkin dan Penguat

Berdasarkan hasil analisis kontribusi variabel pengetahuan $\left(\mathrm{X}_{1}\right)$, $\operatorname{sikap}\left(\mathrm{X}_{2}\right)$, fasilitas $\left(\mathrm{X}_{3}\right)$, lembaga 
lokal $\left(\mathrm{X}_{4}\right)$, tokoh masyarakat $\left(\mathrm{X}_{5}\right)$ dan manfaat ekonomi $\left(\mathrm{X}_{6}\right)$ terhadap partisipasi masyarakat(Y) didapat suatu model persamaan yaitu :

$Y=-5,830+0,163 X_{1}+0,080 X_{2}+$ $0,564 X_{3}+0,086 X_{4}+0,651 X_{6}$

Model ini menunjukkan bahwa lima variabel memberikan kontribusi. Yaitu variabel pengetahuan, sikap, fasilitas, lembaga lokal dan manfaat ekonomi.

Kontribusi secara bersama-sama variabel pengetahuan, sikap, fasilitas, lembaga lokal dan manfaat ekonomi adalah sebesar 65,1\%, sedangkan sisanya adalah sebesar $34,9 \%$ partisipasi masyarakat disebabkan oleh variabel lain diluar kelima variabel diatas. Fasilitas kesehatan merupakan variabel yang memberikan kontribusi terbesar dalama peningkatan partisipasi masyarakat. Variabel selanjutnya secara berurutan adalah manfaat ekonomi, lembaga lokal, pengetahuan dan yang paling kecil kontribusinya yaitu sikap masyarakat.

Partisipasi masyarakat yang terdapat di Denpasar Timur terhadap pengelolaan sampah masih bersifat individu artinya bahwa belum adanya upaya pemberdayaan masyarakat yang bersifat komunal dalam pengelolaan sampah. Upaya yang bersifat komunal masih dalam tahap pengumpulan sampah, sistem retribusi dan menjaga kebersihan lingkungan. Pengolahan sampah dengan upaya reduce, reuse dan recycle masih dalam tahap kesadaran individu dan belum sampai pada tahap partisipasi. Permasalahan partisipasi masyarakat adalah belum adanya penyediaan tempat sampah yang terpisah dan belum dilakukan upaya pemisahan. Pemanfaat kembali sampah hanya dilakukan oleh $67,2 \%$ responden. Partisipasi masyarakat masih pada kegiatan penyediaan tempat sampah $(98,9 \%)$, pengumpulan $(88,9 \%)$, pembayaran retribusi $(55,6 \%)$ dan peran serta pada kegiatan gotong royong di sekitar lingkungan rumah tinggal $(91,7 \%)$.

\section{Simpulan dan Saran}

Pengetahuan memiliki determinasi sebesar $20,6 \%$ terhadap partisipasi masyarakat dalam pengelolaan sampah di Kecamatan Denpasar Timur. Sikap masyarakat memiliki determinasi $24,9 \%$ terhadap partisipasi masyarakat. Fasi-litas pengelolaan terhadap partisipasi masyarakat dengan determinasi $36,2 \%$. Lembaga lokal terhadap par- 
tisipasi masyarakat di pengelolaan sampah dengan determinasi $10,3 \%$. Tokoh masyarakat terhadap partisipasi masyarakat dengan determinasi $8,5 \%$. Manfaat ekonomi terhadap partisipasi masyarakat berdeterminasi $35,9 \%$. Faktor fasilitas, manfaat ekonomi, lembaga lokal, pengetahuan dan sikap memberikan kontribusi secara bersama-sama terhadap partisipasi masyarakat dengan determinasi sebesar 65,1\%. Faktor fasilitas merupakan faktor yang memberikan kontribusi paling dominan terhadap partisipasi masyarakat dalam pengelolaan sampah.

Disarankan Pemda agar melaku-kan pendampingan terhadap lembaga lokal dan memfasilitasi seluruh kebutuhan lembaga lokal dalam upaya peningkatan pengetahuan cara pengo-lahan sampah, penyediaan fasilitas pengelolaan sampah dan pelatihan usaha peningkatan nilai ekonomis sampah. Menyusun peraturan yang mengatur pelaksanaan manajemen pengelolaan sampah bagi pemerintah desa dan desa pekraman berbasis komunal dengan memperhitungkan karakteristik masya-rakat. Menyusun program penyu-luhan dan pelatihan teknis pengolahan sampah dalam skala rumah tangga dan komunal. Serta melakukan upaya kerjasama dengan pihak swasta dalam proses daur ulang sampah.

Perlu dilakukan penguatan lembaga lokal dalam pengelolaan sistem manajemen pengelolaan sampah partisipastif yang bersifat berkelanjutan dan berwawasan lingkungan dengan ujung tombak pelaksanaan pada block leaders., mengatur sistem pengawasan pengelo-laan sampah dengan menerapkan prinsip reinforcement, dan menjalin kerjasama dengan pihak swasta yang dapat membeli sampah yang memiliki nilai ekonomis.

Terhadap masyarakat disarankan agar membiasakan diri untuk melaku-kan upaya pemisahan sampah, dan memperluas wawasan tentang pengolahan sampah rumah tangga melalui lembaga lokal setempat, dan berpartisipasi aktif dalam pengelolaan sampah melalui pemberdayaan

\section{DAFTAR PUSTAKA}

1. Azkha, N. 2007. Pemanfaatan Komposter Berskala Rumah Tangga. Jurnal Kesehatan Masyarakat. September. I (2). 
2. Anonim. 2011. Penanganan Limbah Padat (Persampahan) Kota Denpasar. Denpasar : PT Ganeshaglobal Sarana.

3. Simon, A.M. 2008. Analysis of Activities Of Community Based Organizations Involved In Solid Waste Management. Investigating Modernized Mixtures Approach. The Case of Kinondoni Municipality. Dar es Salaam. Tanzania. Wageningen University and Research Centre.

4. Tamond, Z. E. 2008. Partisipasi Masyarakat dan Teknik Pengelolaan Sampah di Pemukiman. Jurnal Formas. Vol.1 (4) Juni : 277-283.

5. Tandipanga, F.B. 2008. FaktorFaktor Yang Mempengaruhi Peran Masyarakat Terhadap Efektifitas Pengelolaan Sampah. Jurnal Komunitas. Vol.4(1) April: 72-88.

6. Wardani, C. 2004. "Partispasi Masyarakat Pada Kegiatan Pemilahan Sampah Rumah Tangga" (tesis). Jakarta : Program Studi Ilmu Lingkungan Pasca sarjana Universitas Indonesia.

7. Nitikesari, P.E. 2005. "Analisis Tingkat Partisipasi Masyarakat Dalam Penanganan Sampah Secara Mandiri di Kota Denpasar" (tesis). Denpasar : Program Pascasarjana Universitas Udayana

8. Suarna. 2008. Model Penanggulangan Masalah Sampah Perkotaan dan Pedesaan. Pusat Penelitian Lingkungan Hidup. Denpasar : Universitas Udayana. online available at http://scholar. Googleusercontent.com/scholar? $\mathrm{q}=$ cache:BKP9W75a9kcJ:scholar. google.com/+Pengelolaan+Sampa $\underline{h+\text { Sarbagita\&hl=id\&as_sdt=0. }}$. sitasi. 1 Desember 2011.
9. Chan, K. 1998. Mass Communication and Pro-Environment Behaviour: Waste Recycling in HongKong. Journal of Environment $52: 317-325$.

10. de Young, R. 1993. Promoting Source Reduction Behaviour : The Role of Motivational Information. Environmental and Behaviour Vol.25 (1):70-85.

11. Howenstine, E. 1993. Market Segmentation for Recycling. Environment and Behaviour. Vol.25 (1) : 86 - 102.

12. Fatin, S. et all. 2011. A Review On The Succes Factors For Community Participation In Solid Waste Management. Pen ng. M 1 ysi : Proceeding of Inter$n$ tion l Conference On $M n$ gement (ICM 2011).

13. Reid, J.N. 2000. Community Participation : How People Power Brings Sustainable Benefits to Communities. USDA Rural Development Office of Community Development. $1-13$.

14. Gardner, G. T. and P.C. Stern, 1996, Environmental Problems and Human Behaviour. A Simon \& Schuster Company. Massachusets.

15. Papiya, R. Suman and Gurdeep, S. 2007. Community Participation Through Information, Education, Communication And Capacity Building Of ULB For Solid Waste Management. Dhanbad. India : Department of Environmental Science and Engineering. ISMU. International Conference on MSECCMI. New Delhi. India.

16. Reams, M.A. and B.H. Ray, 1993, The Effects of Three Prompting Methods on Recycling Participation Rates : A Field Study, Journal of Environmental System Vol. 22 (4) 371 - 379. 
17. Dewi. A.S dan Warmadewanthi. 2010. Kajian Model Pengelolaan Sampah Berbasis Masyarakat Di Kecamatan Wonocolo Kota Surabaya. Prosiding Seminar Nasional Manajemen Teknologi IX. Surabaya : Program Studi MMT-ITS.

18. Sunarti, NM. 2002. "Peran Serta Masyarakat Dalam Pengelolaan Sampah Rumah Tangga" (tesis). Semarang : Program Studi Magister Ilmu Lingkungan. Fakultas Teknik Universitas Diponegoro.

19. Riwidikno, H. 2008. Statistik Kesehatan. Cetakan Kelima. Yogyakarta : Mitra Cendikia Pres.

20. Green, Lawrence W. 1991. Health Promotion Planning An Educational and Anvironmental Approach. Mayfield Publishing Company. Mountain View.

21. Saribanon, N. Pranawa, S. 2008. Strategi dan Mekanisme Perencanaan Sosial Partisipatif
Dalam Pengelolaan Sampah Permukiman Berbasis Masyarakat Di DKI Jakarta. Jurnal Poelitik Vol.4.(2):337-353.

22. Meidiana, C. 2010. Development of Waste Management Practices in Indonesia. European Journal of Scientific Research. Vol 40 (2) : $199-210$.

23. Kandera. 2004. Pendidikan Kesehatan Masyarakat (PKM) dan Beberapa Aspeknya. Denpasar : Program Studi IlMu Kesehatan Masyarakat Universitas Udayana.

24. Notoatmodjo, S. 2007. Promosi Kesehatan dan Ilmu Perilaku. Jakarta : PT Rineka Cipta.

25. Kusumastuti, D.S.R. 2003. "Kajian Manfaat Biaya Pengolahan Sampah Terpadu Skala Kawasan (Studi Kasus di TPS Rawa Kerbau, Jakarta Pusat)" (tesis). Jakarta: Prodi Ilmu Lingkungan Program Pascasarjana Universitas Indonesia 